${ }^{1}$ Department of Oral and Maxillofacial Surgery, School of Dentistry, University of São Paulo, Brazil

${ }^{2}$ Department of Oral and Maxillofacial Surgery, Hospital M. Dr. Arthur R. de Saboya, São Paulo, Brazil
*Correponding author:

João Gualberto C. Luz

Department of Oral and

Maxillofacial Surgery, School of

Dentistry, University of São Paulo -

USP. Av. Prof. Lineu Prestes, 2227

- Cidade Universitária, 05508-900,

São Paulo - SP, Brazil. Phone: 5511

3091-7887, Fax: 5511 3091-7879.

E-mail: jgcluz@usp.br

Received: November 02, 2020

Accepted: January 11, 2021

\section{Retrospective study of sports-related maxillofacial fractures in a Brazilian trauma care center}

\author{
Julia Souza Ribeiro-dos-Santos ${ }^{1}$ iD, Vinícius Paes de \\ Assis Santos $^{2}$ (iD, João Gualberto Cerqueira Luz ${ }^{1,2 *}$ (iD)
}

Aim: Maxillofacial fractures occur frequently in the general population, and sports-related fractures represent some of these cases. However, few studies have been carried out in Brazilian populations aimed at sports-related maxillofacial fractures. This study assessed the demographic and fracture characteristics of patients with sports-related maxillofacial fractures who were seen at a Brazilian trauma care center. Methods: Medical records of patients with a history of sports-related maxillofacial fractures treated between January 2018 and December 2019 were retrospectively evaluated. Personal data, fracture characteristics, sport type, treatment performed and need for hospitalization were collected. The data were subjected to statistical analyses with likelihood ratio test using the Statistical Package for Social Sciences (SPSS) 25.0 ( $p \leq 0.050)$. Results: Forty cases (4.96\% of the total) of facial fractures were included. The mean age was 24.9 ( \pm 9.8) years, with a predominance of males (92.5\%). The use of protective equipment was rare. The most frequently involved sport modality was soccer (47.5\%), followed by cycling (27.5\%). The most frequent fracture location was nose (45\%), followed by mandible (25\%) and zygomatic complex (17.5\%). Soccer was responsible for most nose fractures (61.1\%), while cycling caused the majority of mandibular fractures (60\%). Conservative treatment predominated (60\%). There was only a significant difference between fracture location and the need for hospitalization ( $p=0.021)$. Conclusion: Patients with sportsrelated maxillofacial fractures were typically young adult males, the injury was more often located in the nose and mandible and related to soccer or cycling. The use of protective equipment must be reinforced.

Keywords: Athletic injuries. Fractures, bone. Mandibular fractures. Zygomatic fractures. Nasal bone. 


\section{Introduction}

Practicing sports is a frequent cause of facial injury. A wide range of facial injuries occur during sports, and their severity varies greatly'. In addition, sports-related maxillofacial injuries represent a significant proportion of the workload in a maxillofacial unit $^{2}$. And the majority of patients are amateur athletes ${ }^{3}$. Sports account for $3 \%$ to $29 \%$ of facial injuries and $10 \%$ to $42 \%$ of facial fractures ${ }^{4}$. It is also important to note that participation in sporting activities has grown worldwide, and the number of cases of sports-related injuries has also increased ${ }^{5,6}$.

At the London Olympics in 2012, 11\% of athletes suffered at least one traumatic injury, confirming the high prevalence of trauma in sports ${ }^{7}$. Indeed, football, soccer, hockey, rugby, baseball, and handball are frequently associated with facial bone fractures $^{2-4,8}$. In addition, the need to educate all players regarding the use of personal protective equipment and adherence to the rules of sports has been proposed to reduce the frequency of impacts during matches ${ }^{2,8}$. On the other hand, sport cycling is the most common noncontact sport causing maxillofacial trauma, with the injuries resulting from slipping ${ }^{6}$. Additionally, participation in mixed martial arts (MMA) striking-predominant disciplines, such as boxing, karate, and Muay Thai, may result in high rates of head and facial injuries, especially during training 9 .

Soccer is the most popular sport in Brazil, and soccer-related maxillofacial trauma is reported to be quite frequent ${ }^{10}$. Additionally, a common sport worldwide, soccer generates a vast number of maxillofacial injuries, predominantly fractures, resulting in esthetic or functional problems $2,5,11$. Although less common than orthopedic injuries in soccer players, maxillofacial trauma may occur. Indeed, knowledge of this situation is important to first responders, nurses, and professionals who have initial contact with patients ${ }^{10}$. On the other hand, the maxillofacial fractures most commonly related to sports are nasal, mandibular and zygomatic fractures ${ }^{4,12}$. Additionally, sports-related dentoalveolar trauma has been most frequently described among basketball and handball players ${ }^{13,14}$.

There are many studies in the literature from abroad reporting the importance of sports in the occurrence of maxillofacial fractures. However, there are still few studies in this regard in Brazilian populations, and some of these works refer to dentoalveolar trauma during sports practice. Thus, this study aimed to assess the demographic and fracture characteristics of sports-related maxillofacial fractures in patients seen at a Brazilian trauma care center.

\section{Materials and methods}

A retrospective study was conducted with information collected from the medical charts of patients treated at the oral and maxillofacial surgery clinic of a trauma hospital that provides coverage for the southern area of São Paulo City, São Paulo State, Brazil. Patients with sports-related maxillofacial fractures seen between January 2018 and December 2019 were included. This study received approval from the Human Research Ethics Committee of the School of Dentistry, University of São Paulo, Brazil (Protocol \# 14086819.7.0000.0075). 
Age, sex, medical history, history of drug abuse, use of mouthguards, and characteristics of the fracture were obtained from the medical charts of patients. Next, the type of sport involved was noted. Taekwondo, Muay Thai and Jiu Jitsu were included in the martial arts category. Fractures were distributed according to their location. Next, the fractures were classified according to zygomatic complex, as described by Knight and North; the maxila, as described by Le Fort; nasal by nasal bone and septal fracture; orbital by blow-out, nasoorbitoethmoid and fronto-orbital fractures; frontal sinus by anterior table and upper orbit; and the mandible by location ${ }^{15-17}$. Dentoalveolar trauma included cases of dental fracture and injuries such as concussion, subluxation, lateral dislocation, extrusion and avulsion. Conventional radiographic views were verified and to improve the description of the fractures, computed tomography features and intraoperative findings were used. Patients with incomplete medical records were excluded.

The performed treatment and the need for hospitalization were noted. Surgical treatment included the reduction of nasal fractures with forceps and surgical access and fixation with plates and screws for the other locations, all under general anesthesia. All patients were treated in a municipal public system. Dentoalveolar trauma cases that required reduction and fixation procedures were also included in the surgical treatment category. Conservative treatment was used for nasal fractures without deviation, fractures of the zygomatic complex with little or no deviation and favorable maxillomandibular fractures that received intermaxillary fixation. Finally, regarding complications, it was verified whether a second surgery was necessary and the reason for it.

The data obtained were tabulated and subjected to statistical analyses. The likelihood ratio test was used to assess possible differences among age groups for the variables "type of sport" and "fracture location", among types of sports for the variables "fracture location" and "treatment performed", and among fracture location for the variables "treatment performed" and "need for hospitalization". The Statistical Package for Social Sciences (SPSS) version 25.0 (IBM Software Group, Chicago, USA) was used for the analysis. The level of significance adopted was $p \leq 0.050$ for all statistical analyses.

\section{Results}

During the period comprised by this study, 806 cases of maxillofacial fractures were assessed, and 40 cases (4.96\%) of sports-related fractures were included. The remaining cases in the sample were excluded because they were due to other causes of fracture. The mean age was $24.9( \pm 9.8)$ years, with a predominance of males, who accounted for 37 cases (92.5\%). The most affected age group was $12-20$ years old with 18 cases (45\%), followed by $21-30$ years old with 11 cases $(27.5 \%), 31-40$ years old with 7 cases $(17.5 \%)$ and 41 years or older with 4 cases $(10 \%)$. The most frequent sport involved was soccer with 19 cases (47.5\%), followed by cycling with 11 cases (27.5\%), martial arts with 2 cases (5\%), and unspecified sport with 8 cases (20\%), according to the findings on the medical charts. All patients were amateur sportsmen. No relevant data were found regarding medical history or drug abuse. Data establishing the use or absence 
of mouthguards were scarce. The location of the fracture in descending order of prevalence was the nose with 18 cases (45\%), the mandible with 10 cases (25\%) - including three cases of bilateral fractures, the zygomatic complex with 7 cases (17.5\%), dentoalveolar trauma with 3 cases $(7.5 \%)$, frontal sinus with 1 case $(2.5 \%)$ and orbit with 1 case (2.5\%). A detailed description of the fracture characteristics is shown in Table 1.

Table 1. Demographic and fracture characteristics of patients with sports-related maxillofacial fractures $(n=40)$.

\begin{tabular}{|c|c|c|}
\hline Age (mean $\pm S D)$ & & $24.9(9.8)$ \\
\hline \multirow[t]{2}{*}{ Gender [n (\%)] } & Male 37 & $(92.5)$ \\
\hline & Female 3 & $(7.5)$ \\
\hline \multicolumn{3}{|l|}{ Location of fractures [n (\%)] } \\
\hline \multirow[t]{4}{*}{ Mandible $(n=13)^{\star}$} & Parasymphyseal & $1(7.7)$ \\
\hline & Body & $4(30.8)$ \\
\hline & Angle & $2(15.4)$ \\
\hline & Condyle & $6(46.1)$ \\
\hline \multirow[t]{6}{*}{ Zygomatic complex $(n=7)^{\star \star}$} & Group I & $2(28.5)$ \\
\hline & Group II & 1 (14.3) \\
\hline & Group III & $2(28.5)$ \\
\hline & Group IV & $1(14.3)$ \\
\hline & Group V & $-(-)$ \\
\hline & Group VI & $1(14.3)$ \\
\hline \multirow[t]{2}{*}{ Nose $(n=18)$} & Nasal bone & $13(72.2)$ \\
\hline & Septal fracture & $5(27.8)$ \\
\hline Frontal sinus $(n=1)$ & Anterior table fracture & $1(100)$ \\
\hline Orbit $(n=1)$ & Blow-out & $1(100)$ \\
\hline \multirow[t]{3}{*}{ Dentoalveolar trauma $(n=3)$} & Lateral luxation & $1(33.3)$ \\
\hline & Avulsion & $1(33.3)$ \\
\hline & Extrusion & $1(33.3)$ \\
\hline
\end{tabular}

SD: Standard deviation. ${ }^{*}$ The number of mandibular fractures exceeds that of patients as three cases were bilateral fractures. ${ }^{*}$ According to Knight \& North.

The nose was the predominant location by age group for both the 12-20-year-old group (55.6\%) and the 41-year-old and above group (50\%). Zygomatic complex fractures occurred more frequently in the $21-30$-year-old group (45.5\%), while mandible fractures were more common in the 31-40-year-old group (42.9\%). The distribution of patients by type of sport and fracture location according to age group is depicted in Table 2. With the application of the likelihood ratio test in relation to the age group, there was no significant difference for the type of sport ( $p=0.774)$ or for the location of the fracture $(p=0.112)$ (Table 2$)$. 
Table 2. Age-specific distribution of patients by type of sport and fracture location according to the likelihood ratio test significance.

\begin{tabular}{|c|c|c|c|c|c|c|c|c|c|c|}
\hline \multirow{3}{*}{ Variable } & \multirow{3}{*}{ Category } & \multicolumn{8}{|c|}{ Age group } & \multirow{3}{*}{$P$ value } \\
\hline & & \multicolumn{2}{|c|}{$12-20$} & \multicolumn{2}{|c|}{$21-30$} & \multicolumn{2}{|c|}{$31-40$} & \multicolumn{2}{|c|}{$\geq 41$} & \\
\hline & & $\mathrm{n}$ & $\%$ & $\mathrm{n}$ & $\%$ & $\mathrm{n}$ & $\%$ & $\mathrm{n}$ & $\%$ & \\
\hline \multirow{4}{*}{$\begin{array}{l}\text { Type of } \\
\text { sport }\end{array}$} & Martial arts & 1 & 5.6 & 0 & 0.0 & 1 & 14.3 & 0 & 0.0 & \multirow{4}{*}{0.774} \\
\hline & Cycling & 5 & 27.8 & 3 & 27.3 & 1 & 14.3 & 2 & 50.0 & \\
\hline & Unspecified sport & 4 & 22.2 & 3 & 27.3 & 1 & 14.3 & 0 & 0.0 & \\
\hline & Soccer & 8 & 44.4 & 5 & 45.5 & 4 & 57.1 & 2 & 50.0 & \\
\hline \multirow{6}{*}{$\begin{array}{l}\text { Fracture } \\
\text { location }\end{array}$} & Zygomatic complex & 0 & 0.0 & 5 & 45.5 & 1 & 14.3 & 1 & 25.0 & \multirow{6}{*}{0.112} \\
\hline & Mandible & 4 & 22.2 & 2 & 18.2 & 3 & 42.9 & 1 & 25.0 & \\
\hline & Nose & 10 & 55.6 & 4 & 36.4 & 2 & 28.6 & 2 & 50.0 & \\
\hline & Orbit & 0 & 0.0 & 0 & 0.0 & 1 & 14.3 & 0 & 0.0 & \\
\hline & Frontal sinus & 1 & 5.6 & 0 & 0.0 & 0 & 0.0 & 0 & 0.0 & \\
\hline & Dento-alveolar trauma & 3 & 16.7 & 0 & 0.0 & 0 & 0.0 & 0 & 0.0 & \\
\hline
\end{tabular}

With regard to the type of sport and the location of the fractures, soccer was responsible for the majority of nasal fractures, with 11 cases $(61.1 \%)$, followed by zygomatic complex fractures, with 3 cases (42.8\%), orbit and frontal sinus fractures, with 1 case each, and dentoalveolar trauma, with 1 case. Cycling was responsible for the majority of fractures of the mandible, with 6 cases $(60 \%)$, followed by zygomatic complex fractures, with 3 cases (42.8\%), and nasal fracture and dentoalveolar trauma accounted for 1 case each. Martial arts were responsible for 1 case of nasal fracture (5.5\%) and 1 case of mandible fracture (10\%). Regarding the treatment performed, there was a predominance of conservative treatment (24 cases - 60\%) upon surgical treatment (16 cases - 40\%). Soccer and cycling required a higher percentage of conservative treatment $(63.2 \%$ and $54.5 \%$, respectively). The distribution of patients by fracture location and type of treatment performed according to the type of sport is shown in Table 3. With the application of the likelihood ratio test in relation to the type of sport, there was no significant difference in the location of the fracture $(p=0.332)$ or the type of treatment performed $(p=0.957)$ (Table 3).

Table 3. Distribution of patients by fracture location and treatment performed according to the type of sport and likelihood ratio test significance.

\begin{tabular}{|c|c|c|c|c|c|c|c|c|c|c|}
\hline \multirow{3}{*}{ Variable } & \multirow{3}{*}{ Category } & \multicolumn{8}{|c|}{ Type of sport } & \multirow{3}{*}{$P$ value } \\
\hline & & \multicolumn{2}{|c|}{ Martial arts } & \multicolumn{2}{|c|}{ Cycling } & \multicolumn{2}{|c|}{ Soccer } & \multicolumn{2}{|c|}{$\begin{array}{l}\text { Unspecified } \\
\text { sport }\end{array}$} & \\
\hline & & $\mathrm{n}$ & $\%$ & $\mathrm{n}$ & $\%$ & $\mathrm{n}$ & $\%$ & $\mathrm{~N}$ & $\%$ & \\
\hline \multirow{6}{*}{$\begin{array}{l}\text { Fracture } \\
\text { location }\end{array}$} & Zygomatic complex & 0 & 0.0 & 3 & 27.3 & 3 & 15.8 & 1 & 12.5 & \multirow{6}{*}{0.332} \\
\hline & Mandible & 1 & 50.0 & 6 & 54.5 & 2 & 10.5 & 1 & 12.5 & \\
\hline & Nose & 1 & 50.0 & 1 & 9.1 & 11 & 57.9 & 5 & 62.5 & \\
\hline & Orbit & 0 & 0.0 & 0 & 0.0 & 1 & 5.3 & 0 & 0.0 & \\
\hline & Frontal sinus & 0 & 0.0 & 0 & 0.0 & 1 & 5.3 & 0 & 0.0 & \\
\hline & Dento-alveolar trauma & 0 & 0.0 & 1 & 9.1 & 1 & 5.3 & 1 & 12.5 & \\
\hline \multirow{2}{*}{$\begin{array}{l}\text { Treatment } \\
\text { performed }\end{array}$} & Surgical & 1 & 50.0 & 5 & 45.5 & 7 & 36.8 & 3 & 37.5 & \multirow{2}{*}{0.957} \\
\hline & Conservative & 1 & 50.0 & 6 & 54.5 & 12 & 63.2 & 5 & 62.5 & \\
\hline
\end{tabular}


Regarding the location of the fractures, the treatment of nasal fractures was predominantly conservative, with 10 cases (55.6\%). The same occurred with mandible fractures in 7 cases (70\%), zygomatic complex fractures in 5 cases $(71.4 \%)$ and orbital fractures (100\%). Surgical treatment was more prevalent in dentoalveolar trauma, with 2 cases (66.7\%), as follows: 1 case of lateral luxation and 1 case of extrusion that were treated by dental repositioning and fixation with application of a resin splint involving intact neighboring teeth, and in frontal sinus fracture (100\%). No cases of second surgery were observed. Most fractures did not require hospitalization: nasal fractures represented 18 cases (100\%); mandibular 7 cases (70\%); zygomatic complex 5 cases (71.4\%); orbital (100\%); and dentoalveolar trauma with 3 cases (100\%). The distribution of patients by type of treatment performed and need for hospitalization according to the location of the fractures is detailed in Table 4. With the application of the likelihood ratio test in relation to the location of the fractures, there was no significant difference for the type of treatment performed $(p=0.454)$, but a significant difference was found for the need for hospitalization $(p=0.021)$ (Table 4).

Table 4. Distribution of patients by treatment performed and the need for hospitalization according to fracture location and likelihood ratio test significance.

\begin{tabular}{|c|c|c|c|c|c|c|c|c|c|c|c|c|c|c|}
\hline \multirow{3}{*}{ Variable } & \multirow{3}{*}{ Category } & \multicolumn{12}{|c|}{ Fraclure location } & \multirow{3}{*}{$P$ value } \\
\hline & & \multicolumn{2}{|c|}{$\begin{array}{l}\text { Zygomatic } \\
\text { complex }\end{array}$} & \multicolumn{2}{|c|}{ Mandíble } & \multicolumn{2}{|c|}{ Nose } & \multicolumn{2}{|c|}{ Orbit } & \multicolumn{2}{|c|}{$\begin{array}{c}\text { Frontal } \\
\text { sinus }\end{array}$} & \multicolumn{2}{|c|}{$\begin{array}{l}\text { Dento- } \\
\text { alveolar } \\
\text { trauma }\end{array}$} & \\
\hline & & $\mathrm{n}$ & $\%$ & $\mathrm{n}$ & $\%$ & $\mathrm{n}$ & $\%$ & $\mathbf{N}$ & $\%$ & $\mathrm{n}$ & $\%$ & $\mathrm{n}$ & $\%$ & \\
\hline \multirow{2}{*}{$\begin{array}{l}\text { Treatment } \\
\text { performed }\end{array}$} & Surgical & 2 & 28.6 & 3 & 30.0 & 8 & 44.4 & 0 & 0.0 & 1 & 100.0 & 2 & 66.7 & \multirow{2}{*}{0.454} \\
\hline & Conservative & 5 & 71.4 & 7 & 70.0 & 10 & 55.6 & 1 & 100.0 & 0 & 0.0 & 1 & 33.3 & \\
\hline \multirow{2}{*}{$\begin{array}{l}\text { Need for } \\
\text { hospitalization }\end{array}$} & No & 5 & 71.4 & 7 & 70.0 & 18 & 100.0 & 1 & 100.0 & 0 & 0.0 & 3 & 100.0 & \multirow{2}{*}{0.021} \\
\hline & Yes & 2 & 28.6 & 3 & 30.0 & 0 & 0.0 & 0 & 0.0 & 1 & 100.0 & 0 & 0.0 & \\
\hline
\end{tabular}

\section{Discussion}

In this study, an analysis of the characteristics of sports-related maxillofacial fractures was performed, aiming at the profile of the affected patients and the anatomical singularities. In addition, the particularities of the treatment, such as the need for surgical treatment and hospitalization, were evaluated. Thus, it was possible to determine that there were characteristics specific to personal data, with most patients being male, younger aged, amateur sportsmen, participants in specific types of sports, prone to fractures at specific locations, and treated with conservative treatment with an infrequent need of hospitalization.

Sports accidents accounted for approximately $5 \%$ of the causes of maxillofacial fractures in this study. Studies carried out in European countries demonstrated a higher prevalence of sports-related maxillofacial fractures, with percentages ranging from 11.4 to $31 \%{ }^{15,18-20}$. A Brazilian study reported that $6.6 \%$ of facial fractures resulted from sports accidents ${ }^{21}$. On the other hand, two other studies with university sportsmen or professional athletes have described even higher frequencies of orofacial trauma associated with sports activities ${ }^{13,22}$. The occurrence of orofacial trauma in Brazilian basketball players has been described as $50 \%$ of athletes ${ }^{13}$. 
Male sex was more frequently affected in this study. This statement is corroborated by other studies in which the percentage ranged from $70.3 \%$ to $100 \%$ of cases $8,11,23$. A male to female ratio of 12.3:1 was observed; other studies established proportions ranging from $6.6: 1$ to $9: 1^{3,8,18}$. When considering various etiologies, the male to female ratio of maxillofacial trauma ranged from 2.1:1 to 4.7:19-21,24,25. One possibility for this result would be that in our study, the most frequent sport involved was soccer and that in Brazil and Europe, soccer is an essentially male sport, with a series of soccer-related maxillofacial fractures with almost all or nearly all patients being male 8,10,11.

The mean age of the patients in this study was at the midpoint of the third decade, with the most affected age group being 12-20 years old. This suggests a lower mean age for sports-related trauma cases, corroborated by many studies in which the mean age of patients ranged from 18.3 to 25.0 years ${ }^{8,23}$. However, in maxillofacial trauma, when considering various etiologies the mean age increases, ranging from 25.5 to 40.7 years ${ }^{15,20,21,25}$

The most prevalent fracture locations found in this study were nasal, the mandible and the zygomatic complex. In the literature, the same locations are the three most prevalente; however, they have different distributions. In such studies, there was a predominance of mandible fractures 24,25 , while zygomatic complex fractures had a higher prevalence in others ${ }^{19,20}$. Only one study determined the predominance of nasal fractures above the other two ${ }^{21}$. In studies that exclusively assessed sports-related trauma, the proportions also differed. In these other studies, there was a predominance of mandible fractures ${ }^{3,18,26}$, fractures of the zygomatic complex ${ }^{2,8,11}$ or nasal fractures ${ }^{27}$. In the present study, in contrast to other studies, there were few cases of dentoalveolar trauma ${ }^{13,14,28}$.

In this study, the sport modalities more frequently involved in maxillofacial fractures were soccer, followed by cycling and martial arts. In studies in other countries, in both Europe (Italy, Greece and Ireland), and in the United States, we found a profile similar to the current study that was conducted in Brazil, with a higher frequency of injury in soccer but with a greater participation in sports-related cases of facial trauma ${ }^{2-4,8,18}$ Soccer has presented a high number of incidents against the head and face during professional practice in Brazil, representing a real risk to athletes ${ }^{29}$.

According to our findings, soccer practice resulted in the highest prevalence of nasal fractures, followed by fractures of the zygomatic complex, similar to other studies ${ }^{27}$. Comparing the results of this study with other research directed at the location of maxillofacial trauma in this sport, conflicting results were found, with the predominance of the zygomatic complex followed by mandibular or nasal fractures $8,11,18$. In general, ball sports, such as soccer and rugby, have contributed to higher rates of zygomatic complex or mandible fractures ${ }^{2,3}$. A Brazilian study on soccer-related facial trauma determined that the most common fracture sites were nasal bones, the zygomatic complex and the mandible ${ }^{10}$. Direct contact between players generally causes soccer-related maxillofacial fractures, such as head-elbow or head-head impacts, which take place mainly when the ball is played with the forehead ${ }^{8}$.

Unlike soccer, cycling had a different fracture profile in this study. It was responsible for most of the mandibular fractures, followed by fractures of the zygomatic com- 
plex and, with the same participation, nasal and dentoalveolar trauma. The literature on cycling-related maxillofacial trauma demonstrated that the mandible is the most frequent bone involved in these accidents, which corroborates our findings ${ }^{26}$. Sports cycling is reported as an important cause associated with maxillofacial trauma ${ }^{6}$.

With regard to the treatment performed, in this study, there was a predominance of conservative treatment. Similar results were observed in a study of general facial trauma, in which nonsurgical procedures were performed at a greater proportion in comparison with patients who underwent surgery ${ }^{24}$. In studies that comprised only sports-related fractures, on the other hand, the proportion of surgical treatment was higher $2,5,11,18$. This fact might reflect the philosophy of the service, thus resulting in a greater or smaller number of cases treated surgically. No cases of second surgery were observed, probably because of following the precepts of the surgical technique, as well as no relevant data on comorbidities or drug abuse among patients.

A few patients needing treatment of maxillofacial fractures required hospitalization, while the majority were treated on an outpatient basis. This finding mainly reflects the decision-making process to perform surgical treatment of nasal fractures under general anesthesia but on an outpatient basis. In most studies on sports-related facial trauma, cases of fracture treated surgically were admitted as inpatients ${ }^{5,18}$, thus generating additional costs for the health system ${ }^{30}$.

Considering the increasing incidence of sports-related injuries, oral and maxillofacial surgeons have to be more concerned with maxillofacial trauma during sports practice $^{6}$. In terms of ball sports, stricter regulations are needed to reduce the percentage of impacts during matches, rather than relying on the use of protective equipment ${ }^{8,18}$. Changes in rules and safety standards have been suggested for the prevention of such injuries ${ }^{5}$. Considering the current reality, the use of protective equipment may safeguard athletes when returning to play after facial injuries have occurred ${ }^{1,23}$.

One of the limitations of this study could be the sample size. Although 40 cases of sports-related maxillofacial fractures were detected, the sample size was not calculated. This could be the reason that there was no significant differences in relation to the age group for type of sport or for location of the fracture. Another possible limitation would be the number of cases of unspecified sports, with 8 cases (20\%), reducing the characterization of sports.

Based on the data collected in this study, it was concluded that the typical patient with sports-related maxillofacial fracture is a young male adult and that the fractures are located more often in the nose and mandible and related to soccer or cycling. Conservative, out-of-hospital treatment prevailed over surgical treatment and inpatient care. Considering the limited use of mouthguards, campaigns are necessary for the prevention of sports-related maxillofacial fractures.

Statement of Ethics: This study was approved by the Research Ethics Committee of the School of Dentistry, University of São Paulo, Brazil.

Disclosure Statement: The authors declare that there are no conflicts of interest regarding the publication of this paper.

Funding Sources: This research was self-funded. 


\section{References}

1. Reehal P. Facial injury in sport. Curr Sports Med Rep. 2010 Jan-Feb;9(1):27-34. doi: 10.1249/ JSR.0b013e3181cd2c04.

2. Murphy C, O’Connell JE, Kearns G, Stassen L. Sports-related maxillofacial injuries. J Craniofac Surg. 2015 Oct;26(7):2120-3. doi: 10.1097/SCS.0000000000002109.

3. Mourouzis C, Koumoura F. Sports-related maxillofacial fractures: a retrospective study of 125 patients. Int J Oral Maxillofac Surg. 2005 Sep;34(6):635-8. doi: 10.1016/j.ijom.2005.01.008.

4. Viozzi CF. Maxillofacial and mandibular fractures in sports. Clin Sports Med. 2017 Apr;36(2):355-68. doi: 10.1016/j.csm.2016.11.007.

5. Elhammali N, Bremerich A, Rustemeyer J. Demographical and clinical aspects of sports-related maxillofacial and skull base fractures in hospitalized patients. Int J Oral Maxillofac Surg. 2010 Sep;39(9):857-62. doi: 10.1016/j.ijom.2010.04.006.

6. Park HK, Park JY, Choi NR, Kim UK, Hwang DS. Sports-related oral and maxillofacial injuries: A 5-year retrospective study, Pusan National University Dental Hospital. J Oral Maxillofac Surg. 2021 Jan;79(1):203.e1-203.e8.doi: 10.1016/j.joms.2020.07.218.

7. Engebretsen L, Soligard T, Steffen K, Alonso JM, Aubry M, Budgett R, et al. Sports injuries and illnesses during the London Summer Olympic Games 2012. Br J Sports Med. 2013 May;47(7):40714. doi: 10.1136/bjsports-2013-092380.

8. Cerulli G, Carboni A, Mercurio A, Perugini M, Becelli R. Soccer-related craniomaxillofacial injuries. J Craniofac Surg. 2002 Sep;13(5):627-30. doi: 10.1097/00001665-200209000-00006.

9. Jensen AR, Maciel RC, Petrigliano FA, Rodriguez JP, Brooks AG. Injuries sustained by the mixed martial arts athlete. Sports Health. 2017;9(1):64-9. doi: 10.1177/1941738116664860.

10. Goldenberg DC, Dini GM, Pereira MD, Gurgel A, Bastos EO, Nagarkar P, et al. Soccer-related facial trauma: Multicenter experience in 2 Brazilian university hospitals. Plast Reconstr Surg Glob Open. 2014 Jul 9;2(6):e168. doi: 10.1097/GOX.0000000000000129.

11. Papakosta V, Koumoura F, Mourouzis C. Maxillofacial injuries sustained during soccer: Incidence, severity and risk factors. Dent Traumatol. 2008 Apr;24(2):193-6. doi: 10.1111/j.16009657.2007.00536.x.

12. Marston AP, O’Brien EK, Hamilton GS. Nasal Injuries in sports. Clin Sports Med. 2017 Apr;36(2):33753. doi: 10.1016/j.csm.2016.11.004.

13. Frontera RR, Zanin L, Ambrosano GM, Flório FM. Orofacial trauma in Brazilian basketball players and level of information concerning trauma and mouthguards. Dent Traumatol. 2011 Jun;27(3):208-16. doi: 10.1111/j.1600-9657.2009.00781.x.

14. Bergman L, Milardović Ortolan S, Žarković D, Viskić J, Jokić D, Mehulić K. Prevalence of dental trauma and use of mouthguards in professional handball players. Dent Traumatol. 2017 Jun;33(3):199-204. doi: 10.1111/edt.12323.

15. Gassner R, Tuli T, Hächl O, Rudisch A, Ulmer H. Cranio-maxillofacial trauma: A 10 year review of 9,543 cases with 21,067 injuries. J Craniomaxillofac Surg. 2003 Feb;31(1):51-61. doi: 10.1016/s10105182(02)00168-3.

16. Ji SY, Kim SS, Kim MH, Yang WS. Surgical methods of zygomaticomaxillary complex fracture. Arch Craniofac Surg. 2016 Dec;17(4):206-10. doi: 10.7181/acfs.2016.17.4.206.

17. Jeon M, Kim Y. Correlation between the existing classifications of nasal bone fractures and subjective patient satisfaction. J Craniofac Surg. 2018 Oct;29(7):1825-8. doi: 10.1097/ SCS.0000000000005043. 
18. Roccia F, Diaspro A, Nasi A, Berrone S. Management of sport-related maxillofacial injuries. J Craniofac Surg. 2008 Mar;19(2):377-82. doi: 10.1097/SCS.0b013e318163e3d7.

19. Kraft A, Abermann E, Stigler R, Zsifkovits C, Pedross F, Kloss F, et al. Craniomaxillofacial trauma: synopsis of 14,654 cases with 35,129 injuries in 15 years. Craniomaxillofac Trauma Reconstr. 2012 Mar;5(1):41-50. doi: 10.1055/s-0031-1293520.

20. Bocchialini G, Castellani A. Facial trauma: A retrospective study of 1262 patients. Ann Maxillofac Surg. 2019 Jan-Jun;9(1):135-9. doi: 10.4103/ams.ams_51_19.

21. Leles JLR, dos Santos EJ, Jorge FD, da Silva ET, Leles CR. Risk factors for maxillofacial injuries in a Brazilian emergency hospital sample. J Appl Oral Sci. 2010 Jan-Feb;18(1):23-9. doi: 10.1590/s167877572010000100006 .

22. Biazevic MGH, Crosato EM, Detoni A, Klotz R, Souza ER, Queluz DP. Orofacial injuries in sports and use of mouthguards among university students. Braz J Oral Sci. 2010 Jul/Sep;9(3):380-3. doi: 10.20396/bjos.v9i3.8641814.

23. Cannon CR, Cannon R, Young K, Replogle W, Stringer S, Gasson E. Characteristics of nasal injuries incurred during sports activities: Analysis of 91 patients. Ear Nose Throat J. 2011 Aug;90(8):E8-12. doi: 10.1177/014556131109000816.

24. Chrcanovic BR, Freire-Maia B, de Souza LN, de Araújo VO, de Abreu MH. Facial fractures: a 1-year retrospective study in a hospital in Belo Horizonte. Braz Oral Res. 2004 Oct-Dec;18(4):322-8. doi: 10.1590/s1806-83242004000400009.

25. Rodrigues L, Leite-de-Lima NS, Landes C, Luz JGC. Changes in admission laboratory tests in patients with maxillofacial fractures and the influence of dento-alveolar trauma. Dent Traumatol. 2020 Jun;36(3):291-7. doi: 10.1111/edt.12540.

26. Boffano P, Roccia F, Gallesio C, Karagozoglu KH, Forouzanfar T. Bicycle-related maxillofacial injuries: a double-center study. Oral Surg Oral Med Oral Pathol Oral Radiol. 2013 Sep;116(3):275-80. doi: 10.1016/j.0000.2013.03.004.

27. Bobian MR, Hanba CJ, Svider PF, Hojjat H, Folbe AJ, Eloy JA, et al. Soccer-related facial trauma: A nationwide perspective. Ann Otol Rhinol Laryngol. 2016 Dec;125(12):992-6. doi: 10.1177/0003489416668195.

28. Cohenca N, Roges RA, Roges R. The incidence and severity of dental trauma in intercollegiate athletes. J Am Dent Assoc. 2007 Aug;138(8):1121-6. doi: 10.14219/jada.archive.2007.0326.

29. Correa MB, Knabach CB, Collares K, Hallal PC, Demarco FF. Video analysis of craniofacial soccer incidents: a prospective study. J Sci Med Sport. 2012 Jan;15(1):14-8. doi: 10.1016/j. jsams.2011.07.011.

30. Saperi BS, Ramli R, Ahmed Z, Nur AM, Ibrahim MI, Rashdi MF, et al. Cost analysis of facial Injury treatment in two university hospitals in Malaysia: A prospective study. Clinicoecon Outcomes Res. 2017 Feb 7;9:107-13. doi: 10.2147/CEOR.S119910. 